\title{
ERCC1 and XRCC1 expression predicts survival in bladder cancer patients receiving combined trimodality therapy
}

\author{
SHIGERU SAKANO*, SATOSHI OGAWA*, YOSHIAKI YAMAMOTO, JUN NISHIJIMA, \\ YOSHIHIRO MIYACHIKA, HIROAKI MATSUMOTO, TAKAHIKO HARA and HIDEYASU MATSUYAMA \\ Department of Urology, Graduate School of Medicine, Yamaguchi University, Ube, Yamaguchi 755-8505, Japan
}

Received December 6, 2012; Accepted February 26, 2013

DOI: $10.3892 / \mathrm{mco} .2013 .85$

\begin{abstract}
Combined trimodality therapy, including transurethral resection and platinum-based chemoradiotherapy, has shown promising results for muscle-invasive bladder cancer. However, this type of treatment may decrease survival as a result of delayed cystectomy in patients with non-responding tumors. DNA repair proteins may affect survival of bladder cancer patients receiving combined trimodality therapy, by affecting the perioperative nature of the tumor cells or by repairing DNA damaged by platinum agents and radiation. We investigated the associations of excision repair cross-complementing group 1 (ERCC1), X-ray repair cross-complementing group 1 (XRCC1) and apurinic/apyrimidinic endonuclease 1 (APE1) expression with response and survival in 157 locally advanced bladder cancer patients receiving combined trimodality therapy, in order to determine the predictive value of the expression of these proteins in patient selection for therapy. We examined ERCC1, XRCC1 and APE1 expression in tumor specimens using immunohistochemistry. Patients positive for ERCC1, positive for XRCC1 and positive for either ERCC1 or XRCC1, exhibited significantly improved disease-specific survival rates $(\mathrm{P}=0.023,0.025$ and 0.0091 , respectively). In multivariate analysis, combined ERCC1 and XRCC1 expression was independently associated with disease-specific mortality [risk ratio (RR): 0.64; 95\% confidence interval (CI), 0.43-0.94 and $\mathrm{P}=0.024]$. Thus, combined ERCC1 and XRCC1 expression may serve as an independent prognostic marker for survival in bladder cancer patients receiving combined trimodality therapy. Prospective studies with a larger sample size are required to confirm these results.
\end{abstract}

Correspondence to: Dr Shigeru Sakano, Department of Urology, Graduate School of Medicine, Yamaguchi University, 1-1-1 MinamiKogushi, Ube, Yamaguchi 755-8505, Japan

E-mail: shigerus@yamaguchi-u.ac.jp

${ }^{*}$ Contributed equally

Key words: combined trimodality therapy, DNA repair enzymes, survival, urinary bladder neoplasms

\section{Introduction}

The standard treatment for muscle-invasive urinary bladder cancer is radical cystectomy followed by urinary diversion; however, this procedure negatively affects the quality of life of patients (1). Several studies reported promising results using combined trimodality therapy in invasive bladder cancer with transurethral resection (TUR), radiation therapy and platinumbased systemic chemotherapy (1-4). Those studies demonstrated 5 -year survival rates of 50-65\% and approximately three-quarters of the surviving patients maintained their own bladders. However, combined trimodality therapy is potentially toxic and may also decrease survival due to delayed cystectomy in patients with non-responding tumors (5). Therefore, it may be beneficial to identify predictors of response and prognosis in order to select appropriate patients for this type of therapy.

The nucleotide excision repair (NER) pathway is essential for maintaining genomic stability and the main mechanism in mammalian cells for removal of bulky, helix-distorting DNA adducts produced by platinum agents $(6,7)$. Excision repair cross-complementing group 1 (ERCCl) is considered a key molecule in this pathway (8). This enzyme plays a ratelimiting role in the NER pathway, recognizing and removing cisplatin-induced DNA adducts (9). ERCC1 is also important in the repair of interstrand cross-links in DNA and in recombination processes. Ionizing radiation causes more prominent DNA base damage and single-strand rather than double-strand breaks (10). These lesions are repaired by the base excision repair (BER) pathway. BER proteins include $\mathrm{X}$-ray repair cross-complementing group 1 (XRCC1) and apurinic/apyrimidinic endonuclease 1 (APE1). XRCC1 plays an important role in BER and acts as a scaffolding intermediate, interacting with ligase III,DNA polymerase $\beta$ and poly(ADP-ribose) polymerase in the C-terminal, $\mathrm{N}$-terminal and central regions of XRCC1, respectively (11). XRCC1 mutant cells exhibit increased sensitivity to ionizing radiation, ultraviolet light, hydrogen peroxide and mitomycin C (12). APE1 is the rate-limiting enzyme in the BER pathway $(11,13)$ and cleaves the 5'-terminal of DNA abasic sugar residues generated by exogenous factors, such as ionizing radiation and environmental carcinogens, as well as by endogenous agents from normal cellular metabolism. Previous studies demonstrated that amino acid substitution variants of the APEI and XRCCl genes are associated with sensitivity to ionizing radiation $(11,14)$. These DNA repair proteins may 
also be involved in reducing the aggressive nature of tumors by inhibiting the accumulation of genetic alterations in tumor cells of patients treated only by surgical resection. Therefore, ERCC1, XRCC1 and APE1 expression in tumor cells may affect response and survival in bladder cancer patients receiving TUR and platinum-based chemoradiotherapy (CRT). Previous studies revealed significant associations between ERCC1 expression and survival in lung, esophageal, gastric, pancreatic and head and neck cancer patients treated by surgery and/or platinum-based (radio)chemotherapy $(8,9,15)$. In addition, XRCC1 and APE1 expression has been strongly associated with survival following radical radiotherapy in bladder cancer (10).

There are no reports thus far on the association between DNA repair protein expression and survival in patients with locally invasive bladder cancer treated with combined trimodality therapy, including TUR and platinum-based CRT. We investigated the association of ERCC1, XRCC1 and APE1 expression with response and survival in bladder cancer patients treated with combined trimodality therapy and determined the predictive value of the expression of these DNA repair proteins in patient selection for therapy.

\section{Materials and methods}

Patients. This retrospective cohort study included 186 patients who underwent combined trimodality therapy including TUR and CRT for locally advanced muscle-invasive (T2-4N0M0) or high-risk non-muscle-invasive (T1G3) (16) urothelial carcinoma of the bladder at Yamaguchi University Hospital between November, 1994 and July, 2009. We included a total of 157 patients for whom clinicopathological information and immunohistochemistry (IHC) of the tumor was assessable. The study was approved by the Institutional Ethics Review Committee of the Graduate School of Medicine, Yamaguchi University and written informed consent was obtained from each patient. The patients were native Japanese and their clinical characteristics are presented in Table I. The median age was 70 years (range, 29-89 years) and the cohort included 118 males $(75.2 \%)$ and 39 females $(24.8 \%)$. Prior to treatment, all patients underwent computed tomography (CT) of the chest, abdomen and pelvis, bone scans, as well as transurethral tumor and random mucosal biopsies of the bladder. In the majority of the patients, bladder tumors were treated with TUR to reduce tumor volume as much as possible.

Patients were staged according to the TNM system of the International Union Against Cancer (UICC; 1997) as follows: 27 patients (17.2\%) were stage T1G3; 59 (37.6\%) were stage T2; 61 (38.9\%) were stage T3; and 10 (6.4\%) were stage T4. All bladder tumors were histopathologically confirmed as urothelial carcinomas. Of these, 145 (92.4\%) showed evidence of urothelial carcinoma alone, 5 (3.2\%) included squamous differentiation and 7 (4.5\%) included an adenocarcinomatous component. The tumors were graded according to the WHO classification as follows: 128 tumors $(81.5 \%)$ were grade 3 and the remaining 28 (17.8\%) were grade 2 .

CRT. The patients received combined platinum-based systemic CRT. In the majority of patients, one cycle of the regimen (based on Shipley's method with slight modification) (17) included administration of cisplatin $\left(70 \mathrm{mg} / \mathrm{m}^{2}\right)$ on day 1 , followed by
Table I. Patient characteristics.

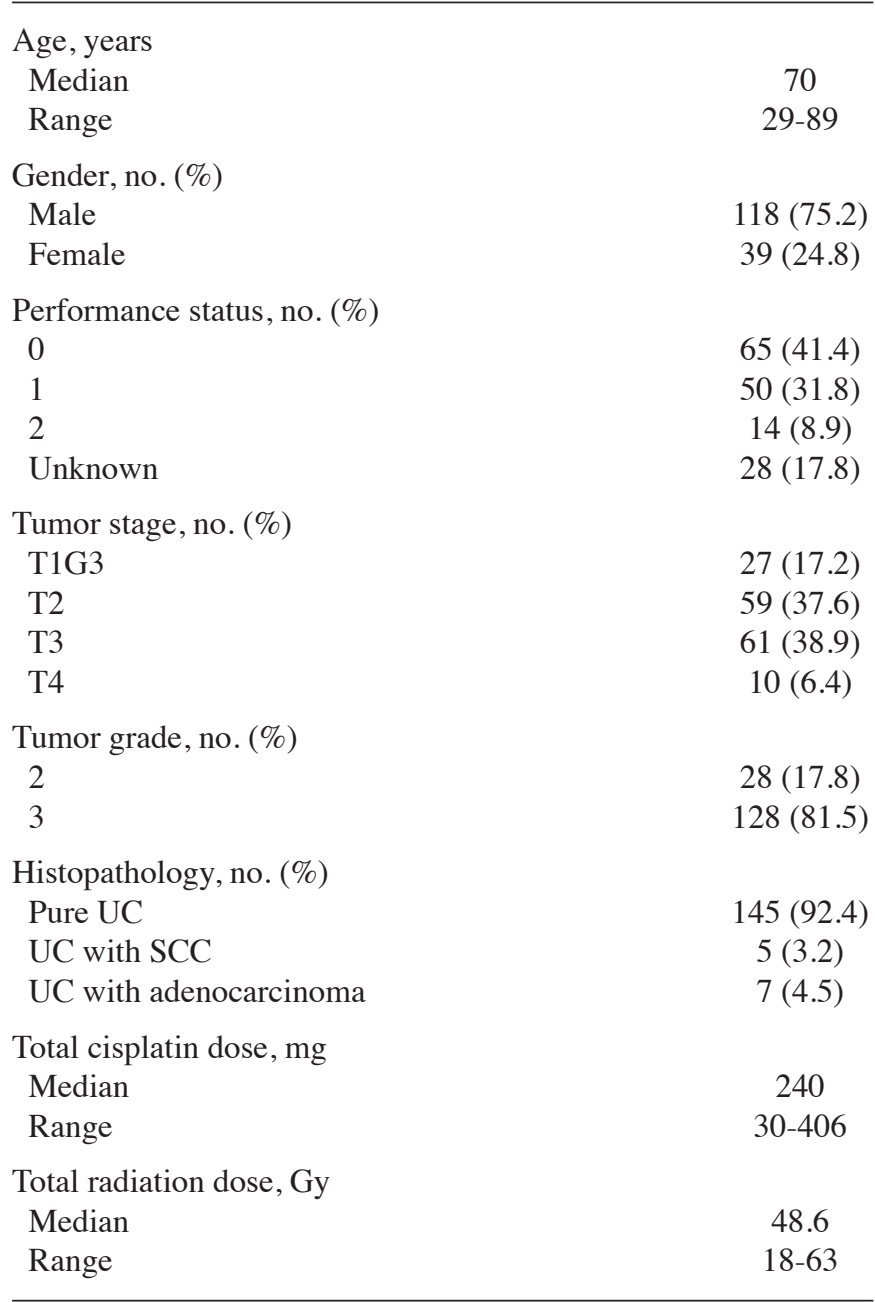

UC, urothelial carcinoma; SCC, squamous cell carcinoma.

radiation at $1.8 \mathrm{~Gy}$ per fraction on days $2-5$ in the first week and every 5 days consecutively in the second week (18-20). Radiotherapy involved 10-MV photons with a 4-field technique, treating the bladder and pelvic lymph nodes to $32.4 \mathrm{~Gy}$ during 2 cycles, followed by a CT-planned whole-bladder boost of $16.2 \mathrm{~Gy}$ for an additional cycle. Although we aimed for 3 cycles of CRT, the treatment was discontinued after 2 cycles in $48(30.6 \%)$ patients who exhibited persistent toxicity or refused to continue with CRT. The median total doses of cisplatin and radiation were $240 \mathrm{mg}$ (range, $30-406 \mathrm{mg}$ ) and 48.6 Gy (range, 18-63 Gy), respectively (Table I).

Four weeks after completion of CRT, we assessed the patient response with $\mathrm{CT}$ scan, random mucosal biopsies and TUR. A complete response (CR) was defined as no pathologically detected residual tumor and non-CR as any pathologically detected residual tumor. CR was observed in $56(35.7 \%)$ and non-CR in 97 (61.8\%) patients. Non-CR patients with residual non-muscle-invasive tumors underwent complete resection of the residual tumor by TUR and residual carcinoma in situ was treated with intravesical instillation of bacillus CalmetteGuérin. Non-CR patients with residual muscle-invasive tumors were referred for radical cystectomy and salvage cystectomy 
Table II. Associations between ERCC1, XRCC1 and APE1 protein expression.

OR $(95 \% \mathrm{CI})$

P-value ${ }^{\mathrm{a}}$

\begin{tabular}{|c|c|c|c|c|}
\hline & \multicolumn{2}{|c|}{ XRCC1 expression (no.) } & & \\
\hline & Negative & Positive & & \\
\hline \multicolumn{5}{|c|}{ ERCC1 expression } \\
\hline Negative & 35 & 32 & Reference & \\
\hline \multirow[t]{3}{*}{ Positive } & 18 & 55 & $3.34(1.63-6.84)$ & $<0.001^{\mathrm{b}}$ \\
\hline & \multicolumn{2}{|c|}{ APE1 expression (no.) } & & \\
\hline & Negative & Positive & & \\
\hline \multicolumn{5}{|c|}{ ERCC1 expression } \\
\hline Negative & 25 & 39 & Reference & \\
\hline \multirow[t]{3}{*}{ Positive } & 29 & 46 & $1.02(0.51-2.02)$ & 0.96 \\
\hline & \multicolumn{2}{|c|}{ APE1 expression (no.) } & & \\
\hline & Negative & Positive & & \\
\hline \multicolumn{5}{|c|}{ XRCC1 expression } \\
\hline Negative & 20 & 33 & Reference & \\
\hline Positive & 29 & 54 & $1.13(0.55-2.31)$ & 0.74 \\
\hline
\end{tabular}

was performed in 22 patients (14.0\%). In addition, 6 patients underwent cystectomy due to recurrence of muscle-invasive bladder cancer during the follow-up period; therefore, a total of 28 patients $(17.8 \%)$ underwent cystectomy during this study. We performed cystoscopic examination followed by washing cytology every 3 months for the first 5 years and every 6 months thereafter. Complementary examinations, including chest X-ray and/or CT scan, were performed every 6 months. The median duration of the follow-up was 39 months (range, 1-193 months). The incidence of bladder cancer-related mortality during follow-up was $18.4 \%$ (29 patients).

$I H C$. Biopsy specimens were selected from the main bladder tumors prior to CRT. IHC was performed on routinelyprocessed, formalin-fixed paraffin-embedded sections using the avidin-biotin complex immunoperoxidase technique, as previously described $(19,21)$. Briefly, serial 5 - $\mu \mathrm{m}$ sections were mounted on poly-L-lysine-coated slides, baked at $50^{\circ} \mathrm{C}$ for $1 \mathrm{~h}$, dewaxed using xylene and rehydrated with graded alcohols to water. The sections were then immersed in a $10 \mathrm{mM}$ citrate buffer ( $\mathrm{pH} \mathrm{6.0)}$ and heated in a water bath at $98^{\circ} \mathrm{C}$ for $30 \mathrm{~min}$. Following antigen retrieval, endogenous peroxidase activity was blocked by $3 \%$ hydrogen peroxide in methanol. Tumor sections were incubated with mouse monoclonal antibody for ERCC1 (1:100; Neomarkers Inc., Fremont, CA, USA), XRCC1 (1:10; Abcam, Cambridge, UK), or APE1 (1:5000; Abcam, Cambridge, UK) at $4{ }^{\circ} \mathrm{C}$ overnight, followed by immunostaining using Vectastain Universal Quick kit (Vector Laboratories Inc., Burlingame, CA, USA). Sections were counterstained with hematoxylin. A duplicate section without primary antibody from the IHC procedure was used as negative control. The number of cells with nuclei positive for ERCC1, XRCC1 and APE1 was determined by scoring 10 microscopic fields of 100 tumor cells each. Staining intensities of each protein were graded on a scale of $0-3$. The percentage of positive tumor nuclei was calculated for each specimen, with 0 indicating $0 \%$ staining; $0.1,1-9 \%$ staining; $0.5,10-49 \%$ staining and $1,50-100 \%$ staining. The proportion score was multiplied by the staining intensity to obtain a semiquantitative H-score (0-3) (9). All measurements were performed by the same investigator (S.O.), using coded samples without prior knowledge of the clinical data. The median H-score for each monoclonal antibody was chosen $a$ priori as the cut-off point for separating positive from negative tumors.

Statistical analysis. The associations between the IHC results (ERCC1, XRCC1 and APE1 expression) and clinicopathological data or response to CRT were assessed using the Chi-square test with an odds ratio (OR) or risk ratio (RR) with $95 \%$ confidence interval (CI). The primary endpoint was disease-specific survival, defined as the time from the initiation of CRT to the date of death from bladder cancer. Disease-specific survival was analyzed by plotting Kaplan-Meier curves and the survival probability distributions were compared using the log-rank test. Categorical variables influencing disease-specific mortality were compared using Cox proportional hazards regression models. Variables with $\mathrm{P}<0.05$ in univariate analysis were also assessed for their association with disease-specific mortality in multivariate analysis. JMP software (SAS Institute Inc., Cary, $\mathrm{NC}$, USA) was used for all analyses, with $\mathrm{P}<0.05$ (two-sided) indicating a statistically significant difference.

\section{Results}

The median H-scores obtained from the IHC slides were 1.0 for ERCC1, XRCC1 and APE1; therefore, an H-score $\geq 1.0$ 


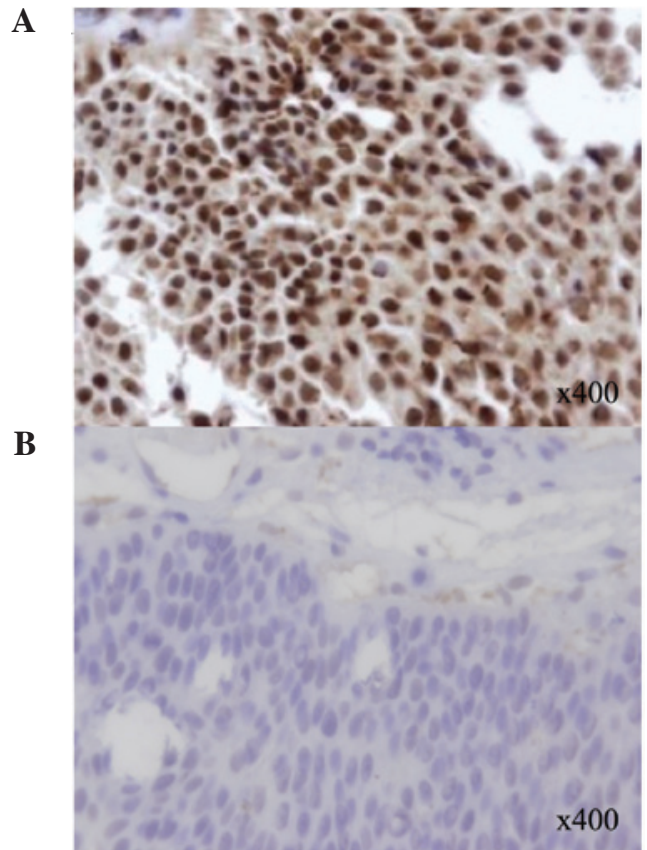

Figure 1. Representative immunohistochemical analyses showing nuclear staining for excision repair cross-complementing group 1 (ERCC1) in bladder cancer (reduced from x400). (A) Case with positive expression and (B) Case with negative expression.

was considered positive for each monoclonal antibody. Seventy-seven out of the $148(52.0 \%)$, 91 out of the $146(62.3 \%)$ and 89 out of the $146(61.0 \%)$ tumors were positive for ERCC1, XRCC1 and APE1, respectively. Representative analyses for ERCC1 IHC are shown in Fig. 1. The associations between ERCC1, XRCC1 and APE1 protein expression are shown in Table II. We observed a significant correlation between ERCC1 and XRCC1 expression ( $\mathrm{P}<0.001$; Chi-square test). No significant correlation was observed between the expression of ERCC1 and APE1, or between XRCC1 and APE1.

There was no significant correlation between the expression of ERCC1, XRCC1 or APE1 and tumor stage or grade in bladder cancer treated with combined trimodality therapy (Chi-square test, Table III). The associations of the expression of ERCC1, XRCC1 or APE1 with response to CRT at 4 weeks after evaluation are also shown in Table III. No DNA repair protein expression was significantly associated with response to CRT using the Chi-square test.

The associations between the expression of ERCC1, XRCC1 or APE1 and disease-specific mortality in bladder cancer patients treated with combined trimodality therapy are shown in Table IV. In univariate analysis using the Cox proportional hazards regression model, ERCC1 expression, XRCC1 expression and combined ERCC1 and XRCC1 expression were significantly associated with disease-specific mortality (RR: 0.65 ; 95\% CI, 0.43-0.94 and $\mathrm{P}=0.023$ for $\mathrm{ERCC} 1$; RR: 0.65; 95\% CI, 0.44-0.95 and $\mathrm{P}=0.028$ for XRCC1; RR: 0.61; 95\% CI, 0.42-0.91 and $\mathrm{P}=0.016$ for combined ERCC1 and XRCC1). Thus, patients who were positive for ERCC1, XRCC1 and either ERCC1 or XRCC1, exhibited improved diseasespecific survival rates. In addition, disease-specific survival rates were plotted for the protein expression using Kaplan-Meier survival curves $(\mathrm{P}=0.023$ for $\mathrm{ERCC} 1, \mathrm{P}=0.025$ for $\mathrm{XRCC} 1$ and

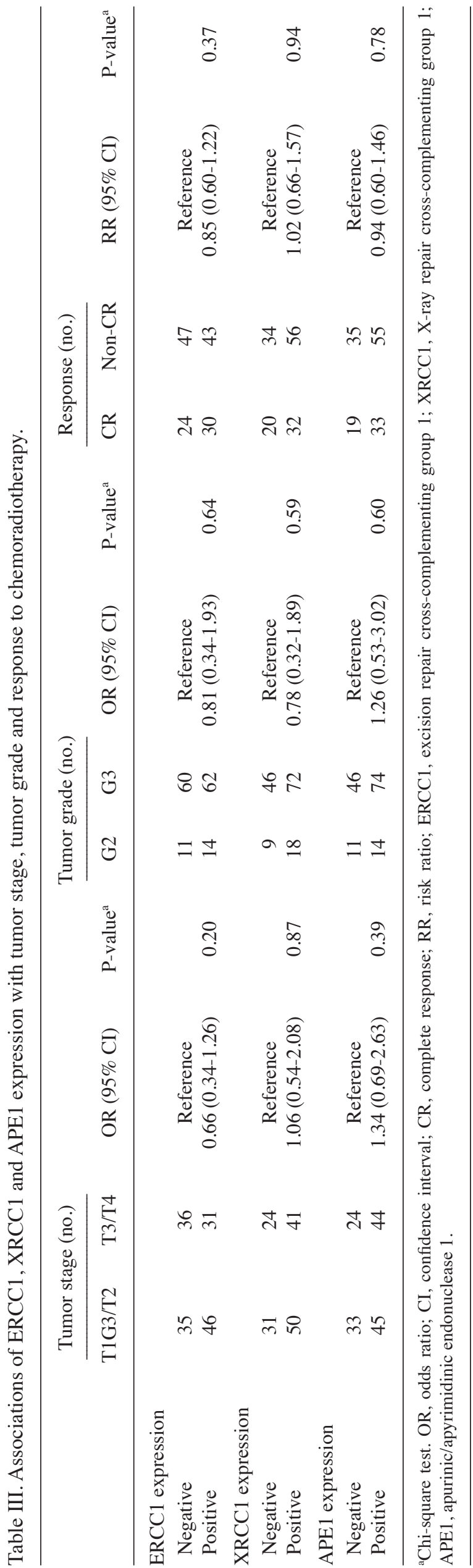


Table IV. Univariate and multivariate regression analyses for predicting disease-specific mortality.

\begin{tabular}{|c|c|c|c|c|c|c|}
\hline \multirow[b]{2}{*}{ Variable (no.) } & \multicolumn{2}{|c|}{ Univariate analysis } & \multicolumn{2}{|c|}{ Multivariate model one } & \multicolumn{2}{|c|}{ Multivariate model two } \\
\hline & RR $(95 \% \mathrm{CI})$ & P-value & $\mathrm{RR}(95 \% \mathrm{CI})$ & P-value & RR (95\% CI) & P-value \\
\hline \multicolumn{7}{|l|}{ Age, years } \\
\hline$<70(74)$ & Reference & & & & & \\
\hline$\geq 70(80)$ & $1.11(0.77-1.61)$ & 0.57 & & & & \\
\hline \multicolumn{7}{|l|}{ Gender } \\
\hline Male (117) & Reference & & & & & \\
\hline Female (37) & $1.02(0.64-1.52)$ & 0.93 & & & & \\
\hline \multicolumn{7}{|l|}{ Tumor stage } \\
\hline T1G3/T2 (85) & Reference & & & & & \\
\hline T3/T4 (69) & $1.86(0.89-3.99)$ & 0.097 & & & & \\
\hline \multicolumn{7}{|l|}{ Tumor grade } \\
\hline G2 (26) & Reference & & & & & \\
\hline G3 (127) & $0.99(0.41-2.95)$ & 0.98 & & & & \\
\hline \multicolumn{7}{|l|}{ Histopathology } \\
\hline Pure UC (141) & Reference & & & & & \\
\hline $\mathrm{UC}+$ other element $(13)$ & $1.42(0.69-2.40)$ & 0.30 & & & & \\
\hline \multicolumn{7}{|l|}{ Cisplatin dose, $\mathrm{mg}$} \\
\hline$\leq 240(64)$ & Reference & & & & & \\
\hline$>240(64)$ & $1.21(0.82-1.80)$ & 0.33 & & & & \\
\hline \multicolumn{7}{|l|}{ Radiation dose, Gy } \\
\hline$<48.6(51)$ & Reference & & & & & \\
\hline$\geq 48.6(94)$ & $1.50(0.99-2.42)$ & 0.055 & & & & \\
\hline \multicolumn{7}{|l|}{$\begin{array}{l}\text { Response to } \\
\text { chemoradiotherapy }\end{array}$} \\
\hline $\mathrm{CR}(56)$ & Reference & & Reference & & Reference & \\
\hline Non-CR (94) & $1.65(1.09-2.72)^{\mathrm{a}}$ & $0.017^{\mathrm{a}}$ & $1.55(1.01-2.57)^{\mathrm{a}}$ & $0.047^{\mathrm{a}}$ & $1.55(1.02-2.56)^{\mathrm{a}}$ & $0.042^{\mathrm{a}}$ \\
\hline \multicolumn{7}{|l|}{ ERCC1 expression } \\
\hline Negative (69) & Reference & & Reference & & & \\
\hline Positive (76) & $0.65(0.43-0.94)^{\mathrm{a}}$ & $0.023^{\mathrm{a}}$ & $0.75(0.48-1.13)$ & 0.17 & & \\
\hline \multicolumn{7}{|l|}{ XRCC1 expression } \\
\hline Negative (54) & Reference & & Reference & & & \\
\hline Positive (89) & $0.65(0.44-0.95)^{\mathrm{a}}$ & $0.028^{\mathrm{a}}$ & $0.74(0.48-1.12)$ & 0.15 & & \\
\hline \multicolumn{7}{|l|}{ APE1 expression } \\
\hline Negative (57) & Reference & & & & & \\
\hline Positive (87) & $0.82(0.56-1.20)$ & 0.30 & & & & \\
\hline \multicolumn{7}{|l|}{$\begin{array}{l}\text { Combined ERCC } 1 \text { and } \\
\text { XRCC } 1 \text { expression }\end{array}$} \\
\hline Negative/Negative (34) & Reference & & & & Reference & \\
\hline Other (111) & $0.61(0.42-0.91)^{\mathrm{a}}$ & $0.016^{\mathrm{a}}$ & & & $0.64(0.43-0.94)^{\mathrm{a}}$ & $0.024^{\mathrm{a}}$ \\
\hline
\end{tabular}

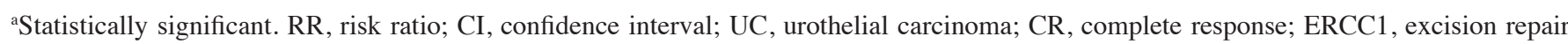
cross-complementing group 1; XRCC1, X-ray repair cross-complementing group 1; APE1, apurinic/apyrimidinic endonuclease 1.

$\mathrm{P}=0.0091$ for combined ERCC1 and XRCC1; log-rank test; Fig. 2). APE1 expression was not significantly associated with disease-specific survival ( $\mathrm{P}=0.29)$. Clinical variables were also assessed for their association with disease-specific mortality (Table IV). Patients who did not achieve a CR to CRT exhibited a significant association with unfavorable outcome using univariate analysis (RR: 1.65; 95\% CI, 1.09-2.72 and $\mathrm{P}=0.017$ ).
In multivariate analysis (model one) of response to CRT, ERCC1 and XRCC1 expression, the response to CRT was the only factor independently associated with diseasespecific mortality (RR: 1.55; 95\% CI, 1.01-2.57 and $\mathrm{P}=0.047$; Table IV). When combined ERCC1 and XRCC1 expression was used instead of individual ERCC1 or XRCC1 expression in multivariate analysis (model two), the response to CRT and 

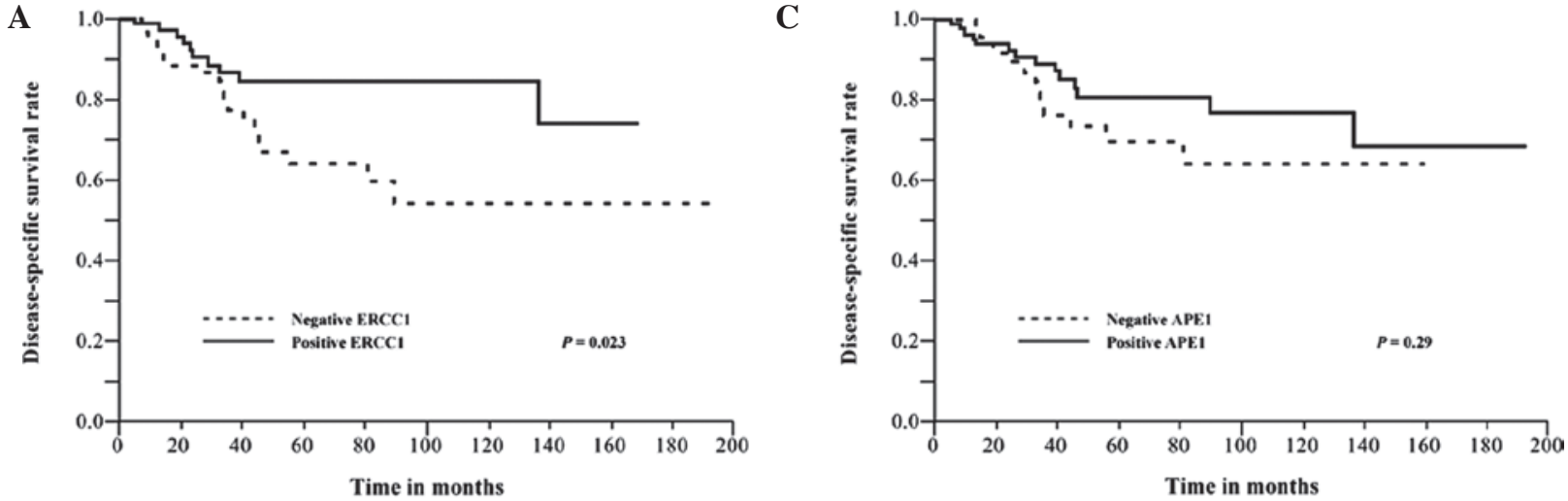

B

D
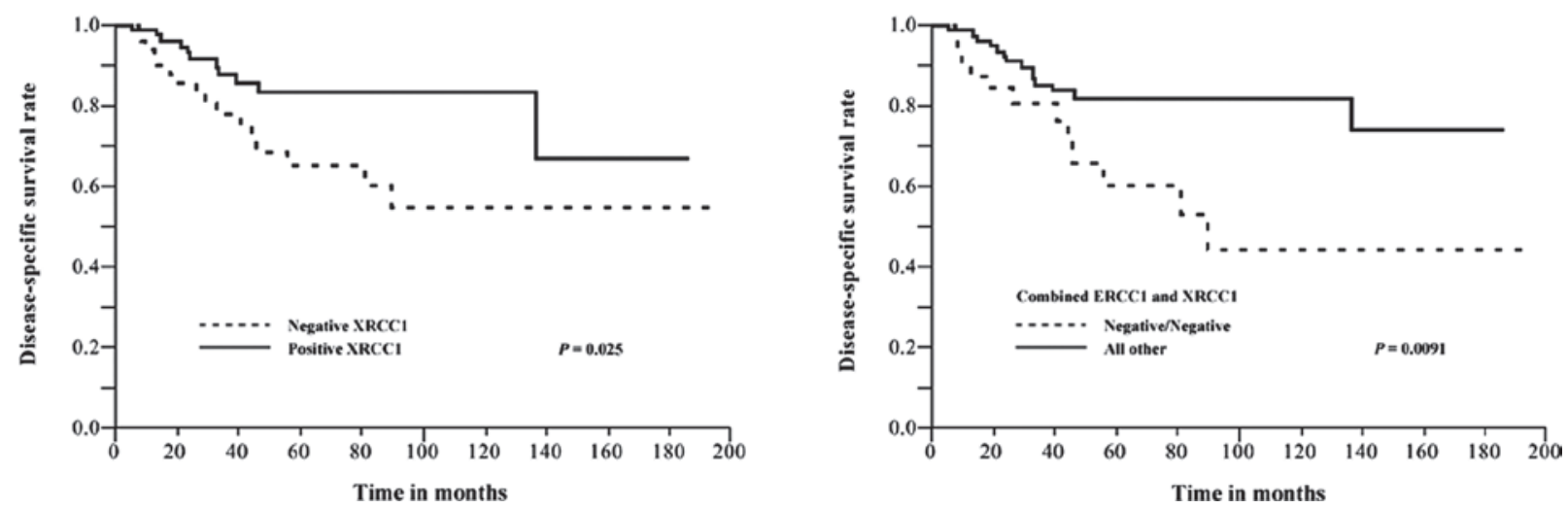

Figure 2. Kaplan-Meier disease-specific survival curves for bladder cancer patients receiving combined trimodality therapy, stratified by (A) excision repair cross-complementing group 1 (ERCC1) expression ( $\mathrm{P}=0.023$, log-rank test); (B) X-ray repair cross-complementing group 1 (XRCC1) expression (P=0.025); (C) apurinic/apyrimidinic endonuclease 1 (APE1) expression ( $\mathrm{P}=0.29)$; and (D) combined ERCC1 and XRCC1 expression ( $\mathrm{P}=0.0091)$.

the combined ERCC1 and XRCC1 expression were independently associated with disease-specific mortality (RR: 1.55 ; 95\% CI, 1.02-2.56 and $\mathrm{P}=0.042$ for response to CRT; RR: 0.64; 95\% CI, 0.43-0.94 and $\mathrm{P}=0.024$ for combined ERCC1 and XRCC1). Thus, patients who were positive for either ERCC1 or XRCC1 exhibited significantly more favorable diseasespecific survival rates compared to those negative for both ERCC1 and XRCC1.

\section{Discussion}

To the best of our knowledge, this is the first study on the association between DNA repair protein expression and survival in patients with locally advanced bladder cancer treated with combined trimodality therapy, including TUR and platinum-based CRT. We demonstrated a significant association between positive expression for ERCC1 or XRCC1 and longer disease-specific survival. Our data indicated that combined ERCC1 and XRCC1 expression is useful as an independent prognostic marker for survival in bladder cancer patients receiving combined trimodality therapy. ERCC1 and XRCC1 are not involved in the same DNA repair pathway. However, both $E R C C 1$ and $X R C C l$ genes are located in close proximity to each other at 19q13.2-13.3 (22) and they may be simultaneously altered by deletion and other changes. A significant correlation was observed between ERCC1 and XRCC1 expression in bladder tumors (Table II). Weakened expression of both ERCC1 and XRCC1 may affect the NER and BER pathways and, therefore, affect the aggressiveness of the tumor or reduce the responce to CRT. Liang et al (23) reported that polymorphisms of ERCCl and XRCC1, in combination but not individually, were independent predictors for clinical responce to oxaliplatinbased chemotherapy in metastatic colorectal cancer.

Previous studies have demonstrated significant associations between ERCC1 expression and the prognosis of lung, upper gastrointestinal and head and neck cancer patients who received platinum-based chemotherapy, with or without radiotherapy $(8,9,15)$. Olaussen et al (9) demonstrated that patients with completely resected non-small cell lung cancer (NSCLC) and ERCC1-negative tumors, appear to benefit from adjuvant cisplatin-based chemotherapy. The authors suggested that ERCC1 is the limiting factor in the NER pathway, which removes platinum-DNA adducts and contributes to cisplatin resistance. Although these results appear to contradict our findings, the authors also reported that, among patients who did not receive adjuvant chemotherapy, those with ERCC1positive tumors survived longer compared to those with ERCC1-negative tumors.

A previous study by Bamias et al (24) reported findings similar to those of the present study, suggesting that patients with radically resected ERCC1-positive gastric cancer who received adjuvant platinum/docetaxel chemotherapy, with or without radiation therapy, exhibited significantly higher overall and disease-free survival rates compared to ERCC1-negative patients. The authors hypothesized that the prognostic role of ERCC1 expression was more significant compared to its 
predictive value. In addition, Simon et al (25) reported that patients with resected NSCLC with high ERCC1 expression exhibited better survival compared to those with low ERCC1 expression. The majority of our patients were treated with combined trimodality therapy, including surgery, potentially affecting our finding that positive ERCC1 or XRCC1 expression was associated with longer survival, since recent evidence suggested that intraoperative tumor manipulation results in detachment of tumor cells that may lead to metastases, particularly tumor cells of high malignant potential $(26,27)$. Additionally, the postoperative phase is characterized by transient changes in the immune system, hampering the antitumor response and rendering the host more susceptible to metastasis.

De Castro et al (28) also demonstrated that the prognostic value of ERCC1 may be dependent on the treatment modality. In surgically treated head and neck squamous cell carcinoma patients, a high expression of ERCC1 was associated with better prognosis, whereas the opposite effect was observed in patients treated with (chemo)radiation, with or without prior induction chemotherapy. The underlying mechanism may be related to the dual nature of ERCC1, favoring reduced mutagenesis and associated with less aggressive tumors, or counteracting cisplatin-induced cell death (29).

Previous studies investigated ERCC1 expression in bladder cancer treated with (chemo)radiation therapy (30-33). Bellmunt et al (30) demonstrated that survival was significantly higher in individuals with low ERCC1 mRNA levels among 57 patients with advanced and metastatic bladder cancer treated with cisplatin-based chemotherapy. Matsumura et al (31) reported no significant differences in survival between high- and low-ERCC1 expression in 40 metastatic bladder cancer patients treated with gemcitabine-cisplatin-based combination chemotherapy. Hoffmann et al (32) indicated that high-ERCC1 mRNA expression was associated with inferior outcomes following cisplatin-based adjuvant chemotherapy in 108 patients with locally advanced bladder cancer. Those results are not in concordance with our findings. However, the patients in those studies were not treated with combined trimodality therapy and the sample sizes were relatively small. Kawashima et al (33) demonstrated that resistance to irradiation, but not to cisplatin, was eliminated by suppressing ERCC1 using siRNA in C18-2 and CDDP10-3 cells. The authors also indicated that negative IHC nuclear staining for ERCC1 correlated with efficacy of CRT using cisplatin in 22 patients with muscle-invasive bladder cancer. However, they did not investigate the association of ERCC1 expression with survival in patients with muscle-invasive bladder cancer treated with CRT.

Sak et al (10) reported that a high expression of APE1 or XRCC1 was associated with improved cancer-specific survival following radical radiotherapy in bladder cancer. The authors suggested that a reduced expression of XRCC1 and APE1 reflects the poorly differentiated nature of tumor cells in more aggressive tumors and that cells from aggressive tumors with extensive genomic instability may harbor chromosomal aberrations that result in failure of gene transcription, including DNA repair genes, resulting in lower protein expression of the gene products. Further investigation of the relationship between ERCC1 and XRCC1 expression and outcomes in bladder cancer patients treated by other modalities, such as cystectomy, is required to determine whether the expression of these proteins is a general prognostic factor reflecting tumor aggressiveness or a predictive factor specific to CRT (10). We observed no significant correlation between ERCC1 or XRCC1 expression and tumor grade, since the majority of the patients included in this study had high-grade disease. ERCC1 and $\mathrm{XRCC} 1$ expression may be a surrogate marker for stratification within the poorly differentiated group of bladder tumors. The conflicting results underline the complexity of DNA repair pathways, with cross-functionality existing between pathways that may exhibit variations in regulation and activation among different tissues or resulting from different drugs, radiation and their combinations $(34,35)$.

In conclusion, the combined pattern of ERCC1 and XRCC1 expression was independently associated with disease-specific mortality in patients with locally advanced bladder cancer treated with combined trimodality therapy. Our results suggested that ERCC1 and XRCC1 expression may predict disease-specific survival in bladder cancer patients treated with combined trimodality therapy. However, our results are limited by the small sample size and allow only preliminary conclusions. Prospective studies including a larger sample size are required to confirm the predictive significance of the expression of these DNA repair proteins.

\section{Acknowledgements}

This study was supported, in part, by a Grant-in-Aid for Scientific Research (C) (24592393) from the Japan Society for the Promotion of Science.

\section{References}

1. Rödel C, Grabenbauer GG, Kühn R, et al: Combined-modality treatment and selective organ preservation in invasive bladder cancer: long-term results. J Clin Oncol 20: 3061-3071, 2002.

2. Tester W, Caplan R, Heaney J, et al: Neoadjuvant combined modality program with selective organ preservation for invasive bladder cancer: results of Radiation Therapy Oncology Group phase II trial 8802. J Clin Oncol 14: 119-126, 1996.

3. Kachnic LA, Kaufman DS, Heney NM, et al: Bladder preservation by combined modality therapy for invasive bladder cancer. J Clin Oncol 15: 1022-1029, 1997.

4. Dunst J, Rödel C, Zietman A, Schrott KM, Sauer R and Shipley WU: Bladder preservation in muscle-invasive bladder cancer by conservative surgery and radiochemotherapy. Semin Surg Oncol 20: 24-32, 2001.

5. Lee CT, Madii R, Daignault S, et al: Cystectomy delay more than 3 months from initial bladder cancer diagnosis results in decreased disease specific and overall survival. J Urol 175: 1262-1267, 2006.

6. Rabik CA and Dolan ME: Molecular mechanisms of resistance and toxicity associated with platinating agents. Cancer Treat Rev 33: 9-23, 2007.

7. Martin LP, Hamilton TC and Schilder RJ: Platinum resistance: the role of DNA repair pathways. Clin Cancer Res 14: 1291-1295, 2008.

8. Metzger R,Bollschweiler E,Hölscher AH and Warnecke-Eberz U: ERCC1: impact in multimodality treatment of upper gastrointestinal cancer. Future Oncol 6: 1735-1749, 2010.

9. Olaussen KA, Dunant A, Fouret P, et al: DNA repair by ERCC1 in non-small-cell lung cancer and cisplatin-based adjuvant chemotherapy. N Engl J Med 355: 983-991, 2006.

10. Sak SC, Harnden P, Johnston CF, Paul AB and Kiltie AE: APE1 and XRCC1 protein expression levels predict cancer-specific survival following radical radiotherapy in bladder cancer. Clin Cancer Res 11: 6205-6211, 2005.

11. Hu JJ, Smith TR, Miller MS, Mohrenweiser HW, Golden A and Case LD: Amino acid substitution variants of APE1 and XRCC1 genes associated with ionizing radiation sensitivity. Carcinogenesis 22: 917-922, 2001. 
12. Thompson LH and West MG: XRCC1 keeps DNA from getting stranded. Mutat Res 459: 1-18, 2000.

13. Ramana CV, Boldogh I, Izumi T and Mitra S: Activation of apurinic/apyrimidinic endonuclease in human cells by reactive oxygen species and its correlation with their adaptive response to genotoxicity of free radicals. Proc Natl Acad Sci USA 95: 5061-5066, 1998.

14. Chang-Claude J, Popanda O, Tan XL, et al: Association between polymorphisms in the DNA repair genes, XRCC1, APE1, and XPD and acute side effects of radiotherapy in breast cancer patients. Clin Cancer Res 11: 4802-4809, 2005.

15. Jun HJ, Ahn MJ, Kim HS, et al: ERCC1 expression as a predictive marker of squamous cell carcinoma of the head and neck treated with cisplatin-based concurrent chemoradiation. Br J Cancer 99: 167-172, 2008.

16. Weiss C, Wolze C, Engehausen DG, et al: Radiochemotherapy after transurethral resection for high-risk T1 bladder cancer: an alternative to intravesical therapy or early cystectomy? J Clin Oncol 24: 2318-2324, 2006.

17. Shipley WU, Prout GR Jr, Einstein AB, et al: Treatment of invasive bladder cancer by cisplatin and radiation in patients unsuited for surgery. JAMA 258: 931-935, 1987.

18. Sakano S, Wada T, Matsumoto H, et al: Single nucleotide polymorphisms in DNA repair genes might be prognostic factors in muscle-invasive bladder cancer patients treated with chemoradiotherapy. Br J Cancer 95: 561-570, 2006.

19. Shinohara A, Sakano S, Hinoda Y, et al: Association of TP53 and MDM2 polymorphisms with survival in bladder cancer patients treated with chemoradiotherapy. Cancer Sci 100: 2376-2382, 2009.

20. Sakano S, Hinoda Y, Sasaki M, et al: Nucleotide excision repair gene polymorphisms may predict acute toxicity in patients treated with chemoradiotherapy for bladder cancer. Pharmacogenomics 11: 1377-1387, 2010.

21. Sakano S, Matsumoto H, Yamamoto Y, et al: Association between DNA repair gene polymorphisms and p53 alterations in Japanese patients with muscle-invasive bladder cancer. Pathobiology 73: 295-303, 2006.

22. Mohrenweiser HW, Carrano AV, Fertitta A, et al: Refined mapping of the three DNA repair genes, ERCC1, ERCC2, and XRCC1, on human chromosome 19. Cytogenet Cell Genet 52 : 11-14, 1989.

23. Liang J, Jiang T, Yao RY, Liu ZM, Lv HY and Qi WW: The combination of ERCC1 and XRCC1 gene polymorphisms better predicts clinical outcome to oxaliplatin-based chemotherapy in metastatic colorectal cancer. Cancer Chemother Pharmacol 66 493-500, 2010.
24. Bamias A, Karina M, Papakostas P, et al: A randomized phase III study of adjuvant platinum/docetaxel chemotherapy with or without radiation therapy in patients with gastric cancer. Cancer Chemother Pharmacol 65: 1009-1021, 2010.

25. Simon GR, Sharma S, Cantor A, Smith P and Bepler G: ERCC1 expression is a predictor of survival in resected patients with non-small cell lung cancer. Chest 127: 978-983, 2005.

26. Coffey JC, Wang JH, Smith MJ, Bouchier-Hayes D, Cotter TG and Redmond HP: Excisional surgery for cancer cure: therapy at a cost. Lancet Oncol 4: 760-768, 2003.

27. Sergeant G, Roskams T, van Pelt J, Houtmeyers F, Aerts R and Topal B: Perioperative cancer cell dissemination detected with a real-time RT-PCR assay for EpCAM is not associated with worse prognosis in pancreatic ductal adenocarcinoma. BMC Cancer 11: 47, 2011.

28. De Castro G Jr, Pasini FS, Siqueira SA, et al: ERCC1 protein, mRNA expression and T19007C polymorphism as prognostic markers in head and neck squamous cell carcinoma patients treated with surgery and adjuvant cisplatin-based chemoradiation. Oncol Rep 25: 693-699, 2011.

29. Gazdar AF: DNA repair and survival in lung cancer - the two faces of Janus. N Engl J Med 356: 771-773, 2007.

30. Bellmunt J, Paz-Ares L, Cuello M, et al: Gene expression of ERCC1 as a novel prognostic marker in advanced bladder cancer patients receiving cisplatin-based chemotherapy. Ann Oncol 18: 522-528, 2007.

31. Matsumura N, Nakamura Y, Kohjimoto Y, et al: The prognostic significance of human equilibrative nucleoside transporter 1 expression in patients with metastatic bladder cancer treated with gemcitabine-cisplatin-based combination chemotherapy. BJU Int 108: E110-E116, 2011.

32. Hoffmann AC, Wild P, Leicht C, et al: MDR1 and ERCC1 expression predict outcome of patients with locally advanced bladder cancer receiving adjuvant chemotherapy. Neoplasia 12: 628-636, 2010.

33. Kawashima A, Nakayama M, Kakuta Y, et al: Excision repair cross-complementing group 1 may predict the efficacy of chemoradiation therapy for muscle-invasive bladder cancer. Clin Cancer Res 17: 2561-2569, 2011.

34. Zhang Y, Rohde LH and Wu H: Involvement of nucleotide excision and mismatch repair mechanisms in double strand break repair. Curr Genomics 10: 250-258, 2009.

35. Herrera M, Dominguez G, Garcia JM, et al: Differences in repair of DNA cross-links between lymphocytes and epithelial tumor cells from colon cancer patients measured in vitro with the comet assay. Clin Cancer Res 15: 5466-5472, 2009. 